\title{
Efeitos do Programa Nacional de Produção e Uso de Biodiesel no território camponês em assentamento rural*
}

\author{
Effects of the Programa Nacional de Produção e Uso de Biodiesel on the peasant \\ territory in the rural settlement
Effets du Programa Nacional de Produção e Uso de Biodiesel dans le territoire paysan de l'assentamento rural

\author{
Efectos del Programa Nacional de Produção e Uso de Biodiesel en territorio campesino en \\ emplazamiento rural
}

\author{
Dinalva Donizete Ribeiro** \\ (dinalvadr@gmail.com) \\ Mariza Souza Dias*** \\ (marizasd@gmail.com)
}

Recebido em 28/11/2014, revisado e aprovado em 15/03/2015; aceito em 20/11/2015

DOI: http:/ / dx.doi.org/10.20435/1518-70122016102

\begin{abstract}
Resumo: Analisou-se a autonomia das famílias assentadas parceiras no Programa Nacional de Produção e Uso de Biodiesel (PNPB). Considerou-se que os espaços de realização das políticas públicas carecem de avaliação por serem, também, locus de disputas que geram tensões, sobretudo quando se trata de um programa com as características do PNPB, que permite a setores do agronegócio ligados à cadeia produtiva da soja o controle das atividades dessa cultura em território camponês.
\end{abstract}

Palavras-chave: Política Pública. Território. Assentamentos Rurais.

Abstract: To begin with, it has been analyzed the autonomy of the settled families who are partners in the National Program of Biodiesel Production and Use (PNPB). It has been considered that the spaces where the public policies are performed lack assessment for being, also, the locus of disagreements that produce tensions, above all when it is related to a program with the PNPB characteristics, which allows the agribusiness sectors connected to the chain of soybean production the control of the activities from this culture in the peasant territory.

Key words: Public Policy. Territory. Rural Settlements.

Résumé: Pour commencer, il a été analysé l'autonomie des familles installées qui sont partenaires dans le Programme National de la Production et l'Utilisation de Biodiesel (PNPB). Il a été considéré que les espaces où les politiques publiques sont effectuées ne sont pas évalués à cause d'être, aussi, le lieu des disputes qui produisent des tensions, surtout quand il est lié à un programme avec les caractéristiques de PNPB, ce qui permet aux secteurs de l'agro-industrie connectés à la chaîne de production de soja, le contrôle des activités de cette culture dans le territoire paysan.

Mots-clés: Les Politiques Publiques. Territoire. Établissements ruraux.

Resumen: Se analizó la autonomía y el control territorial de las familias arraigadas y asociadas al Programa Nacional de Producción y Uso del Biodiesel (PNPB). Se consideró que los espacios de realización de las políticas públicas sufren de insuficiencia evaluativa a causa de ser también, locús de disensión lo que generan tensiones, en especial cuando se trata de un programa con las características del PNPB, que otorga a los sectores de negocios agrícolas vinculados a la cadena productora de soya o control de las actividades de esta cultura en territorio campesino.

Palabras clave: Políticas públicas. Territorio. Emplazamiento rural.

\section{INTRODUÇÃO}

Para a efetivação do Programa Nacional de Produção e Uso de Biodiesesl (PNPB), foram utilizadas estratégias de cooptação de famílias assentadas, firmando-se um conjunto de práti- cas materiais e simbólicas que expressam territorialidades do capital e do Estado em território camponês, observadas em escalas diferentes da escala local, principalmente na global e na nacional, de onde derivam as diretrizes da política pública para a agricultura familiar.

\footnotetext{
* Pesquisa realizada entre os anos de 2010 e 2012 no âmbito do Programa de Pós-graduação em Geografia da Universidade Federal de Goiás, Regional Jataí, com apoio financeiro da Coordenação de Aperfeiçoamento de Pessoal de Nível Superior (CAPES).

** Universidade Federal de Goiás, Goiânia, Goiás, Brasil.

*** Universidade Federal de Goiás, Jataí, Goiás, Brasil.
} 
No entanto Paulino (2006) atenta para o fato de que, ao se discutir a implementação de políticas públicas no processo de territorialização camponesa, é preciso considerar que essa situação não se apresenta como um movimento unidirecional, como se as determinações hegemônicas se materializassem na forma pura tal qual concebidas e planejadas por seus idealizadores, porque elas estão propensas a sofrerem modificações, refutações e confrontos por parte dos camponeses, mesmo que de forma indireta.

Ao se apropriarem das estratégias produtivas (crédito, bens, insumos), as famílias assentadas usam-nas, sempre que possível, de acordo com sua lógica e interesses, buscando, no limite, terem controle do processo produtivo, principalmente em relação ao trabalho. Elas aplicam, nas atividades dos programas de políticas públicas, as ações e racionalidades que são peculiarmente camponesas, como a troca de dias de serviços, a permuta de insumos, a gestão dos instrumentos de trabalho, o controle do tempo e do trabalho, a otimização das culturas e a decisão da família.

Esse conjunto de práticas reflete a territorialidade camponesa expressa a partir de um valor particular, conferido ao território, que ganha uma identidade a partir da apropriação e/ou dominação do espaço (RAFFESTIN, 1993).

Neste trabalho, analisa-se como as famílias do Assentamento Três Pontes tem lidado com o PNPB e adaptado alguns de seus aspectos, com a intenção de se apreender como estão manifestas no território as ações do Estado e do capital, via programas de políticas públicas direcionados para a agricultura familiar, e como as famílias camponesas têm se envolvido com essas ações.

O PNPB possui um aparato de agentes e mediadores privados. Cada família paga os custos da sua lavoura, arcando, inclusive, com os descontos da umidade dos grãos quando entregues no graneleiro. A cada safra, o programa se completa e se renova, com o "apoio" dos agentes: cooperativa e empresas de produção de biodiesel, de assistência técnica, de transporte, de sementes, de insumos químicos, de comercialização de produtos agropecuários, de maquinário e de terceirização dos serviços.
Nas regiões Sul e Centro-Oeste do Brasil, nas quais o agronegócio já se encontra totalmente estruturado, nele inclusa a produção de biodiesel, o PNPB é um programa destinado a assentamentos que já produzem ou têm boas condições para produzir a soja.

\section{MATERIAIS E MÉTODOS}

A pesquisa foi realizada entre os anos de 2010 e 2012, no Assentamento Três Pontes, situado no município de Perolândia, na microrregião Sudoeste de Goiás (figura 1), considerando os efeitos provocados pelo PNPB, entre os anos de 2009 e 2011, no que tange à autonomia e controle territorial por parte das famílias parceiras.

O Assentamento Três Pontes foi criado 1999, possui área total de 1.873,95 hectares, dos quais 454,3 hectares compõem duas áreas de reserva legal. O relevo é constituído, ao sul, por chapadas e, ao norte, pela cuesta da Serra do Caiopó, fazendo divisa com o Ribeirão Invernadinha e com o Córrego do Combate a oeste. Por conta do relevo ondulado e por ser margeado por rios, cerca da metade da área desse assentamento era e, em grande parte, ainda é recoberta de uma mata densa conhecida como cerradão.

O Assentamento é composto por 43 lotes, com área média de 35 hectares cada um. Até o final do ano 2000, foram assentadas 42 famílias, sendo que um lote foi destinado à área da cooperativa e, após seis anos sem, praticamente, nenhum uso, foi destinado a uma família acampada da região. Das 42 famílias originalmente assentadas, 06 comercializaram seus lotes. As famílias compradoras já estão com a situação regulamentada por meio da concessão de uso expedida pelo INCRA.

O mapa 1 apresenta a área do assentamento. Nele é possível distinguir os eixos das estradas e as divisões dos lotes. As áreas em verde escuro são matas densas. Apenas a área mais plana, a oeste, já era desmatada quando as famílias ocuparam a terra. As imagens para a elaboração do mapa foram coletadas no mês de agosto de 2011. Por ser este um mês com baixíssima pluviosidade naquela região, a vegetação aparece acinzentada. Por isso, no mapa, a vegetação da mata parece menor do que realmente é. 
Por estar sobre formação calcária ${ }^{1}$, o solo do assentamento é rico em nutrientes. A água potável é escassa, justamente por estar sobre a laje de calcário, o que dificulta a perfuração e a perenidade da água nos poços.

Foi realizada pesquisa e revisão bibliográfica que contemplassem categorias e conceitos importantes para as análises pretendidas, tais quais: Modo de Vida Camponês e Campesinidades, Campesinato no Brasil, Agricultura Familiar, Questão Agrária, Reforma Agrária, Assentamentos Rurais, Território e Territorialidades, Políticas Públicas e PNPB.

Os trabalhos de campo foram realizados de abril a outubro de 2011, investigando individualmente as famílias selecionadas para compor a pesquisa. Utilizou-se da entrevista semiestruturada, que possibilitou apreender dados quantitativos e qualitativos do envolvimento das famílias com o Programa, bem como elementos das histórias de vida. Foram entrevistadas dez dentre as vinte e uma famílias que participaram do PNPB e duas famílias não envolvidas com o programa.

A pesquisa levou em consideração que o PNPB é um programa que, na região Centro-Oeste, incentiva a exploração das terras dos assentamentos pela commoditie da soja, para a produção do biodiesel.

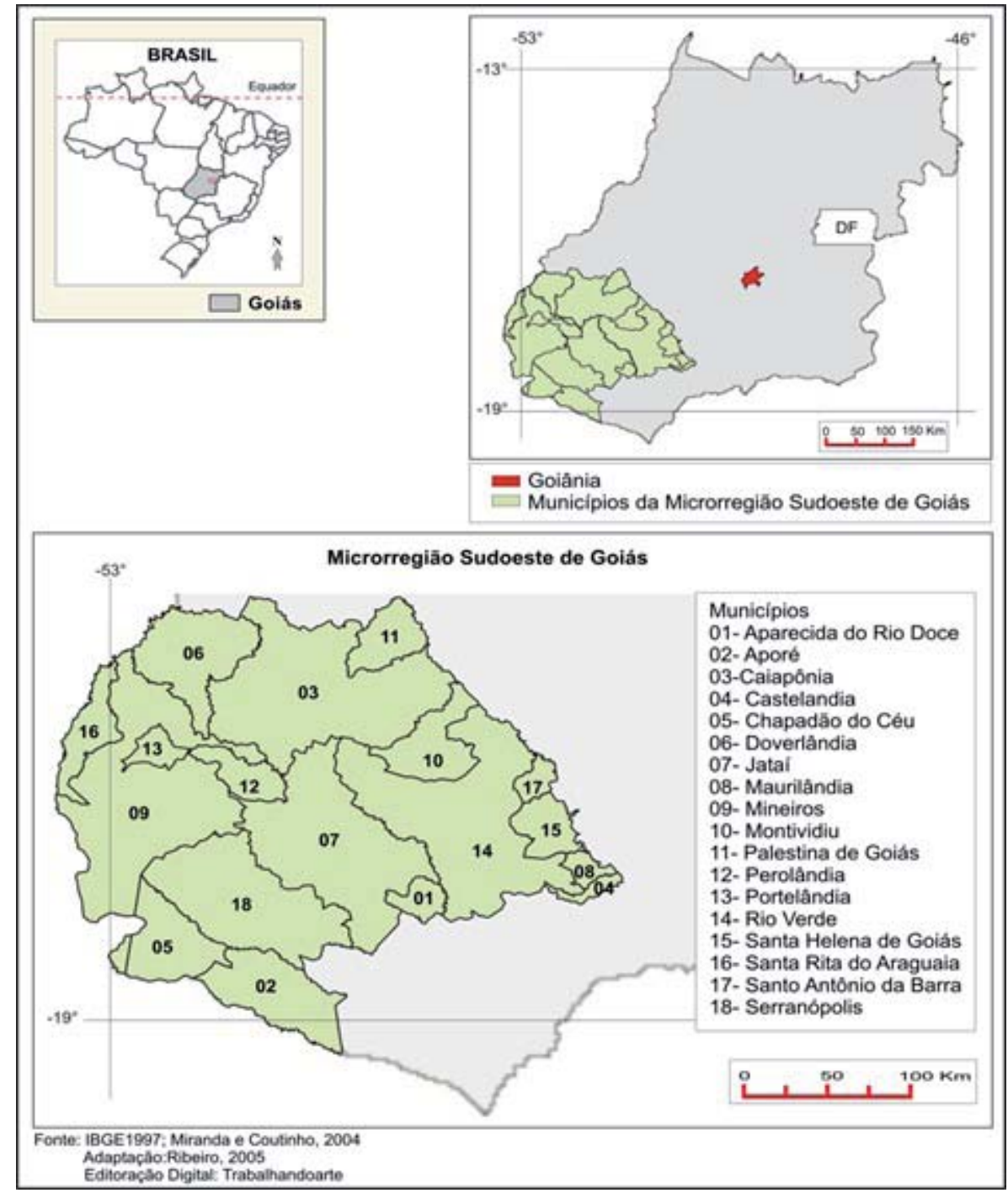

Figura 1 - Localização da Microrregião Sudoeste de Goiás Fonte: RIBEIRO (2005)

\footnotetext{
${ }^{1}$ Período Permiano, formação Ppd. A classificação geomorfológica desta área foi realizada por GUERRA et al. em Um estudo do meio físico com fins de aplicação
}

ao planejamento do uso agrícola da terra no Sudoeste de Goiás (1989). 


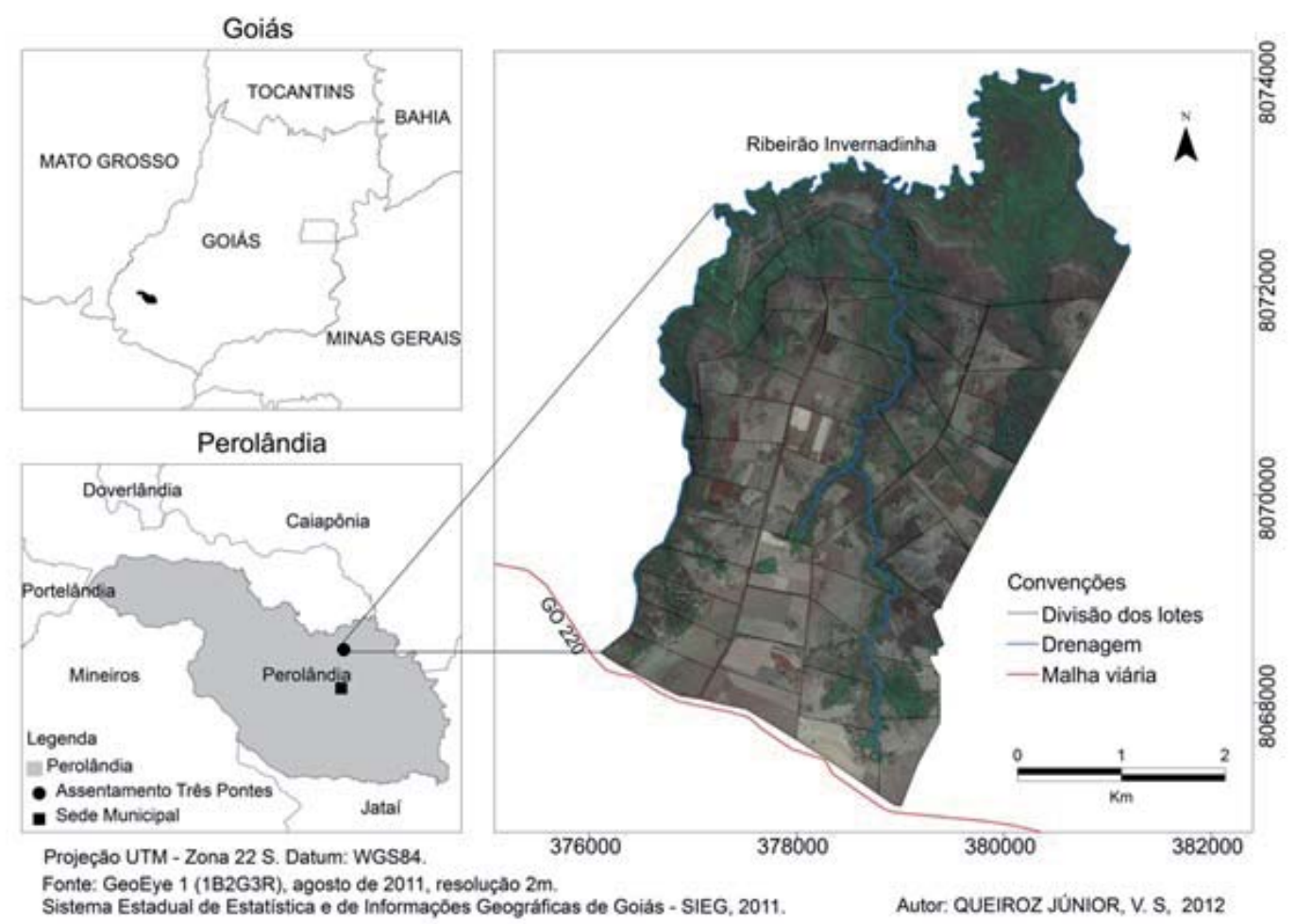

Mapa 1 - Localização do Assentamento Três Pontes

Fonte: Dias (2012).

\section{RESULTADOS E DISCUSSÃO}

O Estado, ao conduzir políticas públicas e seus programas nos assentamentos rurais e atuar como legalizador e mediador, exerce, também, o controle do território desses assentamentos. Os programas são apresentados, neste caso, pelo Ministério do Desenvolvimento Agrário / Secretaria de Agricultura Familiar (MDA/SAF), como forma de inclusão social e como estratégia de desenvolvimento rural e, em tese, estão à disposição de todas as famílias que possuem declaração de aptidão ao Programa Nacional de Fortalecimento da Agricultura Familiar (DAP - PRONAF). O apelo da igualdade social é uma prática simbólica que estimula a inserção e permanência das famílias nos programas, criando quase que uma obrigatoriedade de participação. Conforme o MDA (2011),

A Secretaria da Agricultura Familiar do Ministério do Desenvolvimento Agrário - SAF/MDA - tem por missão consolidar o conjunto da agricultura familiar de modo a promover o desenvolvimento local sustentável por meio da valorização humana e da negociação política com representantes da sociedade, respeitando os desejos e anseios das organizações sociais e praticando os princípios da descentralização, da democracia, da transparência e da parceria, com responsabilidade.

O controle burocrático dos programas fica a cargo do Estado, que estabelece regras de participação, como a prestação de contas, $\mathrm{o}$ cumprimento de cotas e o recolhimento fiscal, dentre outras.

Mas a política pública para a agricultura familiar articula a presença de entidades representativas das famílias, dos movimentos sociais e de conselhos da sociedade civil na elaboração e fiscalização dos programas, tornando a sociedade corresponsável pelo devido andamento ou não dos programas que, assim, mais do que inserirem uma atividade econômica no assentamento, determinam a sua destinação. Caso uma família que possua condições favoráveis ao cultivo de soja não o faça, ela passa a ser olhada de forma negativa, por não ter aderido ao programa. Desconsidera-se, assim, a sua liberdade de escolha de participar ou não de determinado programa. 
A concepção do PNPB é fruto da política mundial que pressiona os países para o uso de agrobiocombustíveis, como o biodiesel produzido de soja: $86,7 \%$ do agrobiocombustível produzido utilizam como matéria-prima essa oleaginosa. Dessa forma, o PNPB permite a setores do agronegócio ligados à cadeia produtiva da soja o controle de sua cultura em território camponês.

Sendo assim, tais setores exercem territorialidades, em diferentes escalas, no assentamento onde está sendo produzida a soja, como no caso das sementes utilizadas, que são controladas por empresas que detêm o processo de biotecnologia e, por consequência, determinam quais e como os insumos devem ser utilizados. No cultivo da soja, as sementes e os insumos são os produtos mais onerosos. Desse modo, parte considerável da renda obtida será apropriada pelo capital.

As empresas propagam que a soja transgênica é mais "resistente" a ataques de insetos e patógenos, e seu uso impõe às famílias a compra das sementes e do pacote de insumos necessários à produção. Mesmo que a família opte por comprar sementes não transgênicas, no momento da venda, a Caramuru (empresa compradora) não faz a distinção entre uma e outra por receber majoritariamente soja transgênica e cobrará royalty da semente, que gira em torno de $2,5 \%$ sobre o valor de cada saca produzida.

Dentre os problemas que a semente transgênica carrega, um dos principais refere-se à falta de autonomia da família que a utiliza, já que não poderá controlar todo o seu processo produtivo, ficando dependente do mercado de sementes e insumos.

A territorialização do capital em terras camponesas via PNPB se expressa, também, no controle do preço da saca da soja, por meio da bolsa de valores de Chicago (EUA). O programa está conseguindo manter estável o preço da soja no Brasil, pois a demanda pelo biodiesel está em crescimento.

Como a produção de soja oriunda da agricultura familiar tem mercado garantido, em função do selo combustível social (SCS), o programa torna as famílias alvo de disputas por empresas privadas, tanto as lojas de produtos agropecuários que financiam os insumos, como as empresas que comercializam grãos e/ou produzem biodiesel.
A ação do Estado, por meio da regulamentação do PNPB e das medidas legais e econômicas que o seguem, fez com que a paisagem do Assentamento Três Pontes se alterasse, ficando desenhada pelas lavouras de soja. Dentre as quarenta e três famílias, vinte e sete, ou seja, $63 \%$ a cultivam-na. Ali a produção de soja aumentou de 251 hectares na safra 2.010/2011 para 394 hectares na safra 2011/2012, um acréscimo de 57\% da área cultivada.

Conforme Paulino (2010), a vitalidade do negócio agrícola se alimenta de estratégias de controle territorial. Como se vê, o PNPB tem um forte potencial de modificar as atividades do território, uma vez que, dos 394 hectares cultivados com soja no assentamento em 2011, aproximadamente 50\% eram cultivados anteriormente com pastagem.

Para garantir a assimilação do PNPB pelas famílias assentadas, as empresas buscam a parceria, argumentando, quantitativamente, sobre a eficiência produtiva que o programa proporciona, justificando, assim, a intensificação das atividades do agronegócio em territórios camponeses, como nos assentamentos de reforma agrária.

A empresa que efetua o contrato, no caso pesquisado, é a Caramuru, e a cooperativa que o articula é a Cooperativa Mista Agropecuária do Rio Doce (COPARPA). Ambas exercem, juntas, sobre as famílias assentadas, um conjunto de práticas materiais e simbólicas em nível local e regional.

A Caramuru está presente em assentamentos de nove municípios do Sudoeste de Goiás, envolvendo cerca de duzentas famílias. Cinco desses assentamentos estão situados nos municípios de Jataí e Perolândia.

A COPARPA iniciou a participação no programa em 2006, agregando oitenta famílias. Em 2012, já contava com cerca de setecentas famílias produzindo soja pelo PNPB. A Cooperativa tem contrato com duas grandes empresas produtoras de biodiesel no estado de Goiás com as quais é feita a comercialização da soja produzida pelas famílias assentadas: a Caramuru e a Granol.

Nos dois casos, foram as empresas que procuraram a Cooperativa para que esta assumisse a corresponsabilidade no processo produtivo da soja. A Cooperativa articula a compra dos insumos e a assistência técnica, 
que é custeada pelas empresas e define percentuais de pagamento entre os agentes, evidenciando uma prática monetária comum no âmbito do Programa. A Cooperativa é quem orienta as empresas quanto aos assentamentos considerados apropriados para integrar com o PNPB.

De acordo com o depoimento de um dirigente da Cooperativa, percebe-se que dois aspectos são levados em consideração na hora de estabelecer o contrato com as famílias assentadas: se "são trabalhadoras", mesmo se estiverem em débito com bancos, e se as terras "são boas". O que interessa à empresa é a capacidade de produção das terras e a disposição das famílias para o trabalho com a produção de soja.

As empresas envolvidas com o PNPB apresentam os seguintes argumentos: melhoria da renda, diversificação produtiva, fornecimento de assistência técnica, prêmios por produção e financiamento de maquinários para as famílias produtoras de soja, exigindo, em contrapartida, contrato de exclusividade da produção, conforme previsto legalmente pelo PNPB.

As práticas simbólicas usadas pela empresa são expressas logo na fase de aproximação com as famílias, quando da apresentação do Programa, quando se utiliza da expressão "parceria" para falar do contrato de produção com as famílias. A utilização dessa expressão por parte da Caramuru, assim como é visto na página eletrônica do MDA quando se trata do PNPB, remete a um sentimento de igualdade entre os sujeitos, fazendo com que as famílias se sintam mais envolvidas e incluídas no processo.

Todavia a empresa não respeita nem mesmo os direitos assegurados pelo Programa. A parceria que é veiculada por esse Programa é, na verdade, um eufemismo da cooptação das famílias e da exploração da renda camponesa pelo capital.

A parceria entre as famílias assentadas e a empresa é norteada pela necessidade imposta pelo Estado no negócio do biodiesel. Mesmo não produzindo em quantidade significativa, já que a empresa compra somente aquilo que lhe obrigado pelo SCS, as famílias passam a fazer parte do negócio da empresa. O depoimento de um funcionário da empresa demonstra por que as famílias são incluídas nesse processo.
Dentro da compra da soja, a quantidade produzida pela agricultura familiar em geral não é representativo. Mas, para o nosso segmento, para o nosso negócio, é importante. É importante nós termos a agricultura familiar. Faz parte do nosso negócio. Vamos continuar a trabalhar até sermos o número '1' em agricultura familiar (A. L.). (Grifo nosso)

O entendimento de "bom negócio" por parte da empresa se baseia nas vantagens que irá obter a partir do contrato estabelecido, alcançando benefícios fiscais, créditos e garantias comerciais que a empresa tem ao acessar a DAP das famílias. O que significa dizer que o princípio original norteador da empresa não é o compromisso social, como sugere o Programa.

Localmente, a empresa e a Cooperativa exercem controle sobre o território camponês, refletindo ali a escala global do controle exercido pelo agronegócio. Quando a Cooperativa organiza o crédito, acompanha tecnicamente a lavoura e direciona a tomada de decisão em relação aos problemas que surgem, impõe subordinações econômicas às famílias, expressando controle territorial em escala local em relação ao assentamento.

No caso pesquisado, a COPARPA exerce, também, a função de mediadora de conflitos. Essa estratégia é utilizada no sentido de garantir a produção e a produtividade da cultura, zelando pela continuidade da parceria, logo, pelo uso da terra e do trabalho camponês apropriados por meio do PNPB.

No entanto a perda do controle e da autonomia é relativa, já que, mesmo usando o pacote tecnológico na produção da soja, as famílias se mobilizaram para decidir como realizar e com quem realizar determinadas etapas do trabalho da lavoura, refletindo formas de controle local do território, demonstrando que não há subordinação completa das famílias ao Programa e seus mediadores, o que indica conflitos entre a lógica imposta pelo programa/Estado/capital e a lógica camponesa de apropriação do território.

Verificou-se que, em algumas etapas da produção, as famílias se organizaram em grupos para adquirir maquinários, decidiram qual área do sítio deveria ser ocupada pela soja e questionaram e/ou negaram a assistên- 
cia técnica, buscando formas de manutenção do controle do trabalho e da produção.

\section{CONSIDERAÇÕES FINAIS}

Os esquemas de controle do território por parte dos programas/Estado/capital estão presentes na efetivação do programa por meio da empresa (Caramuru), da cooperativa (COPARPA) e dos prestadores de serviço (técnicos e outros), que se orientam pelo mercado e pelo agronegócio. Esses agentes externos à realidade das famílias assentadas retiram delas parte do controle e da autonomia em relação à produção e ao trabalho. Isso ocorre nas etapas burocráticas, produtivas e de comercialização da soja.

Contudo o Programa é um canal de comercialização e, por isso, as famílias o julgam importante e não o negam completamente. $\mathrm{O}$ PNPB é percebido pelas famílias como uma estratégia de produção e geração de renda que possibilita a permanência na terra.

Por ocasião da realização da pesquisa, o PNPB tinha dois anos de ação no Assentamento Três Pontes e o resultado de apenas uma safra. De acordo com a pesquisa, as famílias estão se subordinando a essa condição de produtores de grãos para aumentarem a renda e diversificarem e/ou potencializarem outras atividades a partir do retorno financeiro que a soja proporciona.

As famílias reorganizaram as formas de trabalho a partir do que foi inicialmente proposto pela empresa e pela Cooperativa, estabelecendo parcerias entre si, organizando-se em grupos, comprando e gerindo seus maquinários, buscando mão de obra dentro do próprio assentamento, garantindo certa autonomia na condução das lavouras. Essa autonomia se expressa na confiança e na liberdade ao se negar a contratação de trabalhadores externos, uma vez que, se as parcerias se derem entre pessoas e famílias do próprio assentamento, o pagamento pode se dar em permutas de dias de trabalho, divisão do trabalho e produtos.

\section{REFERÊNCIAS}

DIAS, Mariza Souza. Apropriações camponesas da política pública para a agricultura familiar no Assentamento Três Pontes, Perolândia (GO). Jataí. 152f. 2012. Dissertação (Mestrado em Geografia) - Universidade Federal de Goiás, Campus Jataí.

GUERRA, Antônio José Teixeira et al. Um estudo do meio físico com fins de aplicação ao planejamento do uso agrícola da terra no Sudoeste de Goiás. Rio de Janeiro: IBGE, 1989.

MINISTÉRIO DO DESENVOLVIMENTO AGRÁRIO - MDA, 2011. Disponível em: <http://www.mda.gov. br/potal/saf/>. Acesso em: 25 jul. 2013.

PAULINO, Eliane Tomiasi. Políticas territoriais e questão agrária: da teoria à intervenção. In: SAQUET, Marcos Aurélio; SANTOS, Roseli Alves (Orgs.). Geografia agrária, território e desenvolvimento. São Paulo: Expressão Popular, 2010. p. 107-129. Por uma geografia dos camponeses. São Paulo: Editora UNESP, 2006.

PROGRAMA NACIONAL DE PRODUÇÃO E USO DE BIODIESEL - PNPB, 2011. Disponível em: <http:/ / www.biodiesel.gov.br/>. Acesso em: 28 set. 2013.

RAFFESTIN, Claude. Por uma geografia do poder. Ática: São Paulo, 1993.

RIBEIRO, Dinalva Donizete. Agricultura "caificada" no Sudoeste de Goiás: do bônus econômico ao ônus sócio-ambiental. 317f. 2005. Tese (Doutorado em Geografia) - Universidade Federal Fluminense, Niterói. 